\title{
Evaluation of Clinical Pharmacist's Contribution to Sepsis and Septic Shock Management
}

\author{
Nursel Sürmelioğlu ${ }^{1}$, Kutay Demirkan ${ }^{2}$, Emre Karakoç ${ }^{3}$, Murat Gündüz ${ }^{3}$, and Dilek \\ Özcengiz ${ }^{3}$ \\ ${ }^{1}$ Cukurova University \\ ${ }^{2}$ Hacettepe University Faculty of Pharmacy \\ ${ }^{3}$ Faculty of Medicine, Çukurova University
}

June 20, 2021

\begin{abstract}
Purpose: This study aimed to identify drug-related problems at treatment in patients with sepsis and septic shock and to evaluate the contribution of the clinical pharmacist. Methods: This study was conducted at intensive care units(ICU) of a university hospital. A study group in which the clinical pharmacist participated in the treatment management of septic patients and a control group in which the clinic did not have a pharmacist was formed. In the treatment of the control group, interventions were made for drug-related problems detected by the clinical pharmacist. Study and control group were compared in terms of length of ICU stay, time to initiation of appropriate antimicrobial drug(s), appropriateness of antimicrobial dosing, and drug treatment costs. Results: Total of 65 patients were included in the study group prospectively in which the intervention of clinical pharmacist provided for the drug treatments and retrospectively 65 patients in the control group without any intervention. In the study group, 670 recommendations were made for 753 problems related to their drug therapy. Between groups, improvement in appropriateness of antimicrobials in terms of dose, time to initiation of appropriate antimicrobial therapy, daily antibiotic costs in all patients and antibiotic costs in patients with impaired renal function statistically significant difference were found. Conclusions: As a result of clinical pharmacist involvement in sepsis management, it has been shown to contribute to the prevention and management of drug interactions, to start antimicrobial therapies more quickly, to select the appropriate drug and dose, especially antimicrobials, and to save the costs of antimicrobial drugs.
\end{abstract}

\section{Hosted file}

Main text.docx available at https://authorea.com/users/360538/articles/526971-evaluation-ofclinical-pharmacist-s-contribution-to-sepsis-and-septic-shock-management

\section{Hosted file}

Tables.docx available at https://authorea.com/users/360538/articles/526971-evaluation-ofclinical-pharmacist-s-contribution-to-sepsis-and-septic-shock-management

\section{Hosted file}

Figure 1.docx available at https://authorea.com/users/360538/articles/526971-evaluation-ofclinical-pharmacist-s-contribution-to-sepsis-and-septic-shock-management

\section{Hosted file}

Figure 2.docx available at https://authorea.com/users/360538/articles/526971-evaluation-ofclinical-pharmacist-s-contribution-to-sepsis-and-septic-shock-management 